\title{
Twins and Their Health Cost: Consequences of Multiple Births on Parental Health and Mortality in Denmark and England and Wales
}

\author{
Cecilia Tomassini, ${ }^{1,2}$ Emily Grundy,' Axel Skytthe, ${ }^{3}$ and Kaare Christensen ${ }^{3}$ \\ ' Centre for Population Studies, London School of Hygiene and Tropical Medicine, London, United Kingdom \\ ${ }^{2}$ Department of Economic and Social Sciences, University of Molise, Campobasso, Italy \\ ${ }^{3}$ Epidemiology, Institute of Public Health, University of Southern Denmark, Odense, Denmark
}

\begin{abstract}
The rapid increase in twinning rates in developed countries has increased interest in the question as to whether twin mothers have higher mortality and more health problems than mothers of singletons. Here we use a national survey, the Office for National Statistics Longitudinal Study of England \& Wales, and a linkage between the Danish Twin Registry and the Danish population register to examine mortality patterns after age 45 (50 for fathers) for twin parents and the whole population born from 1911 to 1950. For England and Wales, presence of limiting long-term illnesses and selfrated health status was also investigated. Overall similar health and mortality was found for twin parents and the whole population although both life table methods and survival analysis suggested a slight excess mortality among older cohorts of twin mothers in England and Wales.
\end{abstract}

Increasing recognition of the importance of life course influences on health in mid and later life has led to recent interest in the possible implications of reproductive history for the later life health of women (Beral, 1985; Kuh \& Hurdy, 2002). A range of studies have shown a link between high parity and health later in life, even after control for socioeconomic status (Doblhammer, 2000; Grundy \& Tomassini, 2005; Kvale et al., 1994; Riley, 2003). Several studies have also shown that late motherhood is associated with lower subsequent mortality, probably due to the fact that the ability to conceive and deliver a child after the age of 40 may be an indicator of 'slower' ageing and overall better health (Perls et al., 1997; Snowdon et al., 1989). In contrast, recent studies from the United States reported associations between late childbearing and mortality and a range of adverse health indicators after the age of 50 including diabetes, hypertension, congestive heart failure, poor dental health, vision difficulties and impaired physical mobility (Alonso, 2002; Cooper et al., 2000). High parity and older age at motherhood are both associated with twinning, but having twins may in itself have additional health implications. Some studies have shown that women with short birth intervals have elevated risks of death and poor health later in life (Grundy \& Tomassini, 2005). Hypothesized mechanisms include the particular physical, psychological and economic strains of raising large families or closely spaced children. Bearing and raising twins or higher multiple births clearly represents an extreme of closely spaced children that might be hypothesized to invoke particular risks. Several studies have shown that mothers of twins have higher risks of depression or other psychological problems, especially in the first years of their children's lives, than other mothers (Thorpe et al., 1991; Olivennes, 2000). Specific hormonal pathways, linked especially to reported risks of some cancers in some studies, may also be important (Kvale et al., 1994) although other studies have found no differences between mothers of twins and mothers of singletons and breast and gynecological cancers (Nasca et al., 1992; Neale et al., 2005; Neale et al., 2004). Another study found a weak association between twinning and the risk of ovarian cancer (Lambe et al., 1999).

Investigating the effect of fertility on later life health is difficult, because of the need to control for possibly confounding effects which may vary considerably over time and between countries. Twinning rates in particular have varied considerably over time and place.

The number of multiple births as a percentage of all live-births is currently at an all-time high in many European countries (Fellman \& Eriksson, 2005). In

Received 3 November, 2005; accepted 23 March, 2006.

Address for correspondence: Cecilia Tomassini, Centre for Population Studies, London School of Hygiene and Tropical Medicine, 49-51 Bedford Square, London, WC1B 3DP, UK.E-mail: Cecilia.tomassini@lshtm.ac.uk 
England and Wales the twinning rate between 1938 and 1960 remained stable at a level around 12 per thousand births, while in Denmark, the rate was slightly higher in the 1940s and 1950s (around 15 per thousand). In the early 1970s multiple births reached its lower point (around 10 per thousand) for both countries, but increased steadily after, reaching 15 per thousand in England and Wales and a remarkable 21 per thousand in Denmark in 2003 (UK Office for National Statistics and Statistics Denmark). These variations in the overall twinning rate are due to changes in dizygotic twinning, with the monozygotic twinning rate remaining fairly stable over time (Skytthe et al., 2002).

These time trends reflect changes in fertility patterns, and particularly changes in the distribution of mothers by age. Older women are more likely to have dizygotic multiple births than younger women and trends in twinning rates reflect trends in the distribution of births by age of mother. Changes in the nutritional status of women may also be an influence as recent research suggests that increased maternal body mass index is associated with a higher twinning rate (Basso et al., 2004). However, in the last two decades the wider use of fertility treatments to stimulate ovulation and multiple implantations of embryos with in vitro fertilization (IVF) is the main reason for the increasing incidence of multiple births in developed countries (Herskind et al., 2005; Westergaard et al., 1997). A recent report for 18 European countries showed that around $30 \%$ of births as a result of medical treatments were multiple births (Nygren \& Nyboe Andersen, 2001).

These changes in the incidence of twinning and underlying changes in the characteristics of women bearing twins, complicate the study of possible longterm sequelae of bearing twins as many of these characteristics are themselves associated with healthrelated differences. Traditionally, dizygotic twinning has been associated with maternal age, parity, race, familial clustering, and nutrition with higher rates of dizygotic twinning among older, high parity women, especially those with a family history of twinning and those from certain ethnic groups (Hall \& Lopez-Rangel, 1996). Bearing dizygotic twins has also been shown to be associated with other indicators of high fecundity, such as generally higher age-specific fertility rates and shorter birth intervals overall (Basso et al., 2004; Sear et al., 2001). Conversely, mothers of twins born as a result of interventions such as IVF are selected for low fecundity and may also be selected for other health problems. These differences in the characteristics of mothers of twins over time have been little explored but are important to take into account when examining possible long-term consequences of bearing twins. The very increase in twinning rates referred to above indicates a need for further examination of these possible longterm consequences of bearing twins or higher multiples.

In this study we examine first, the mortality after age 45 of mothers of twins compared with that of all women in England and Wales and Denmark, and second, in relation to the mortality of mothers of singletons in England and Wales among cohorts of women born between 1911 and 1950. We also examine the mortality after age 50 of fathers of twins, in relation to mortality of all men in Denmark. Additionally we also consider differences in the characteristics of mothers of twins and mothers of singletons in England and Wales and different health outcomes.

\section{Materials and Methods}

The data we use come from the Danish Twin Register, the Office for National Statistics Longitudinal Study (ONS-LS) of England and Wales and official estimates of cohort mortality probabilities for the two countries.

\section{Danish Sources}

Denmark has a long and reliable registration of twins (Skytthe et al., 2002). The twin cohorts from 1953 to 1982 have been identified, (around 17,000 twin pairs) based on information about the parents from the Danish Civil Registration System (CRS), which was established in 1968. For the oldest cohorts, information about parents is present for about half of the twins, but this has increased rapidly to more than $90 \%$ from 1960. Since 1968, information about parents is available for nearly all twins. Vital status information at January 1, 2002, for all known parents was obtained from the CRS. Because the Danish data set includes only twins and their parents, examination of the possible mortality risks associated with bearing or fathering twins is only possible using data from an external source, namely estimates of mortality in the whole population from the same birth cohorts. These were derived using cohort life tables calculated with standard demographic techniques using information on deaths from Statistics Denmark.

It is not possible to control for socioeconomic characteristics in analysis of the effects of having a multiple birth on mortality, but the strength of the Danish data set is the large sample and consequently increased statistical power.

\section{Sources for England and Wales}

For England and Wales we use the ONS-LS, a record linkage study of approximately $1 \%$ of the population initially based on those enumerated in the 1971 Census of England and Wales (approximately 500,000 people). Sample members were traced in the National Health Services Central Register and record linkage used to add information from subsequent censuses and from vital registration, including births to sample mothers and death. The fertility history data come from a combination of 1971 census and subsequent vital registration information. The 1971 Census included questions on the fertility histories of ever-married women aged 16 to 59; subsequent linkage of births to women in the sample was complete to the end of 2001, as is linkage of deaths of sample members. For the 
women included in this analysis we therefore have complete fertility histories to the end of the reproductive period. There are, however, some sources of potential omission. The first arises because in 1971 only evermarried women were asked to provide fertility history data and they were only asked to record births within marriage. We therefore have no data on nonmarital births prior to 1971 . For cohorts born between 1920 and 1940, nonmarital fertility generally accounted for only $4 \%$ to $6 \%$ of all births in England and Wales, so the effect of this omission is relatively slight (Office for Population Censuses and Surveys, 1987). Post-1971 fertility information comes from linkage of births, both marital and nonmarital, and some births may have been missed due to linkage failure, estimated to be around $8 \%$ to $9 \%$ (Hattersley \& Creeser, 1995). The death linkage has been proved to be more reliable and only $1 \%$ of deaths are not traced. Advantages of the ONS-LS, in comparison with the Danish data, are that it allows control for socioeconomic characteristics and also comparisons of the mortality and health of mothers of twins (around 1800 women) in the sample with those of other parous women, something not possible using the Danish data.

In the interests of comparability, we undertook the cohort mortality analysis for England and Wales using data from cohort life tables to examine relative mortality risks of mothers of twins in the ONS-LS sample. The Government Actuary's Department provided cohort life tables for England and Wales.

\section{$\overline{\text { Methods }}$}

A first set of analyses compared the expected and the observed numbers of deaths for mothers (in both countries) and for fathers of twins (for Denmark only) using the cohort mortality probabilities for the total national population from 1968 to 2001 (in Denmark) and from 1971 to 2001 (in England and Wales) and after age 45 (50 for fathers) for the latest cohorts. We considered cohorts born from 1911 to 1950, grouped in 10 -year subsets. For example, a woman born in 1915 in England and Wales is followed from age 56 (her age at the 1971 census) to the end of 2001. A woman born in 1945 is followed after she reaches age 45 (in 1990) to the end of 2001. Age 45 was chosen for women and 50 for men since nearly all fertility occurs before these ages. In this study triplets and quadruplets have been grouped with twin births.

An additional survival analysis comparing mothers of twins and mothers of singletons was conducted for parous women from England and Wales to study their survival after age 45 controlling for a set of covariates using data available from the linked censuses. These covariates include marital status in 1991; social class, where social class was based on own current or past occupation (manual, nonmanual, no occupation); having a higher education, where high education identified those with qualifications equivalent to or higher than 'A level' (a school qualification gained at around age 18) or not; housing tenure (owner occupier vs. tenant) and car access (household has use of car/no use of car). We additionally controlled for other aspects of fertility history (number of children, having had any teenage births; and short intergenesic interval (less than 18 months for nonmultiple births) known to be associated with later life health (Grundy \& Tomassini, 2005).

Furthermore, for England and Wales, logistic regression analysis was used to investigate associations between twinning and having poor self-rated health in 2001 or having limiting long-term illness at 1991 and 2001 censuses, again controlling for a set of covariates known to have a strong relation with health. The census question asked people whether they had a longterm illness, health problem or disability which limited their daily activities or work; we refer to this as limiting long-term illness. Information on self-rated health was not collected in the 1991 census and no questions on mental morbidity have been included in the English and Wales census so this latter aspect of health could not be examined.

\section{Results \\ Mortality}

Table 1 reports the observed and expected number of deaths, the standardized mortality ratios and their relative confidence intervals. The first column of the table shows that the observed numbers of deaths among mothers of twins in England and Wales is not significantly different from the deaths expected if the general mortality of the English population is applied.

Standardized mortality ratios are not significantly different in Denmark for either mothers or fathers of twins.

In the analyses presented above, mothers (and fathers) of twins are compared with the whole population, including the nulliparous, a group in itself known to have higher than average mortality (Grundy \& Tomassini, 2005). In order to estimate more realistically possible health costs of having twins, comparisons with mothers of singletons only are required. This is only possible using data for England and Wales from the ONS-LS and below we show results from survival analysis applied to parous women in England and Wales. This analysis shows some significant effects of having multiple births on mortality after age 45 among cohorts of mothers born between 1911 and 1920 (Table 2), even after controlling for a set of socioeconomic indicators.

\section{Health}

Using the census data from the ONS-LS it was possible to draw a picture of several characteristics of mothers of twins compared with the mothers of singletons. Table 3 provides some comparisons between mothers of twins and mothers of singletons for cohorts born between 1911 and 1950 who were included in the 1971, 1991 and 2001 censuses. As expected, the main sociodemographic indicators are 
Table 1

Observed and Expected Number of Deaths After Age 45 (50 for Fathers) for Parents of Twins Using Cohort Life Tables for the General Population of England and Wales (1971-2001) and Denmark (1968-2001)

\begin{tabular}{|c|c|c|c|c|c|c|c|c|c|c|c|c|c|c|c|}
\hline \multirow{3}{*}{$\begin{array}{l}\text { Cohorts } \\
1911-1920\end{array}$} & \multicolumn{5}{|c|}{ Women - England and Wales } & \multicolumn{5}{|c|}{ Women - Denmark } & \multicolumn{5}{|c|}{ Men - Denmark } \\
\hline & \multirow{2}{*}{$\begin{array}{c}\text { OBS } \\
354\end{array}$} & \multirow{2}{*}{$\begin{array}{l}\text { EXP } \\
325\end{array}$} & \multirow{2}{*}{$\begin{array}{c}\text { SMR } \\
109\end{array}$} & \multicolumn{2}{|c|}{$\begin{array}{c}95 \% \\
\text { confidence } \\
\text { interval }\end{array}$} & \multirow{2}{*}{$\begin{array}{r}\text { OBS } \\
354\end{array}$} & \multirow{2}{*}{$\begin{array}{l}\text { EXP } \\
363\end{array}$} & \multirow{2}{*}{$\begin{array}{c}\text { SMR } \\
97\end{array}$} & \multicolumn{2}{|c|}{$\begin{array}{c}95 \% \\
\text { confidence } \\
\text { interval }\end{array}$} & \multirow{2}{*}{$\begin{array}{c}\text { OBS } \\
1100\end{array}$} & \multirow{2}{*}{$\begin{array}{c}\text { EXP } \\
1136\end{array}$} & \multirow{2}{*}{$\begin{array}{c}\text { SMR } \\
97\end{array}$} & \multicolumn{2}{|c|}{$\begin{array}{c}95 \% \\
\text { confidence } \\
\text { interval }\end{array}$} \\
\hline & & & & 98 & 121 & & & & 88 & 108 & & & & 91 & 103 \\
\hline $1921-1930$ & 212 & 195 & 109 & 95 & 124 & 1016 & 1081 & 94 & 88 & 100 & 1840 & 1891 & 97 & 93 & 102 \\
\hline 1931-1940 & 69 & 61 & 113 & 88 & 143 & 774 & 795 & 97 & 91 & 104 & 887 & 939 & 94 & 88 & 101 \\
\hline 1941-1950 & 13 & 15 & 88 & 46 & 148 & 269 & 264 & 102 & 90 & 115 & 203 & 222 & 91 & 79 & 105 \\
\hline
\end{tabular}

Note: Confidence intervals have been calculated directly from the Poisson distribution when the number of observed deaths was less than 100 (in italics in the table), while the normal distribution was used when the number of observed deaths was higher than 100.

OBS = Observed, EXP = Expected, SMR = Standardized Mortality Ratio.

Source: For England \& Wales: Office for National Statistics — Longitudinal Study, Government Actuary's Department cohort life tables, For Denmark: Danish Civil Register, Danish cohort life tables (author's calculations).

similar for mothers of singletons and mothers of twins in 1991. The proportion of women giving birth after age 40 is higher among mothers of twins, reflecting the increased probability of having multiple births with older age. The mean number of children is clearly influenced by the presence of a multiple birth, therefore mothers of twins have on average one more child compared to mothers of singletons. Additionally, mothers of twins have a slightly higher presence of limiting longterm illness compared to mothers of singletons in 1991 and 2001, while the probability of being in bad health was similar in the two groups.

We used logistic regression to model the probability of reporting limiting long-term illnesses in 1991 and 2001 and the probability of reporting poor health in 2001 by having had a multiple birth, controlling for several explanatory variables. Results presented in Table 4 show that having had a multiple birth does not significantly affect the presence of long-term illnesses in 1991. In 2001, for women born between 1921 and 1940, the probability of having limiting long-term ill-

\section{Table 2}

Odds Ratios for Risk of Death After Age 45 for Mothers of Twins Compared to Mothers of Singletons From Survival Analysis Including Covariates - England and Wales

\begin{tabular}{lc}
\hline & $\begin{array}{c}\text { Odds ratios } \\
(95 \% \text { Confidence Interval) }\end{array}$ \\
\hline Cohorts & $1.12^{*}(1.00-1.27)$ \\
$1911-1920$ & $1.10(0.96-1.28)$ \\
$1921-1930$ & $1.17(0.91-1.49)$ \\
$1931-1940$ & $0.98(0.79-1.21)$ \\
$1941-1950$ & \\
\hline Note: Controlling for marital status, social class, education, tenure, car access, parity, \\
teenage pregnancy, birth after age 40, and intergenesic interval and period. \\
* $p<.05$.
\end{tabular}

nesses is higher for mothers of a multiple birth even after controlling for demographic and socioeconomic factors. There is no significant association, however, with self-reported health status in 2001.

\section{Conclusions and Discussion}

This study found no significant higher mortality after reproductive ages for parents of twins when comparing with the mortality of the general population. This was true for both mothers (for England and Wales and Denmark) and for fathers (investigated only in Denmark) of twins. This result suggests that there is no significant effect detectable on the mortality levels of mothers after age 45 with the present sample size. However, survival analysis of data from England and

\section{Table 3}

Demographic and Socioeconomic Characteristics of Mothers of Twins and Mothers of Singletons for Cohorts Born Between 1911 and 1950: England and Wales 1991 and 2001 Censuses

\begin{tabular}{lcc}
\hline \multicolumn{2}{c}{ Mothers of twins } & Mothers of singletons \\
\hline Women present in 1991 & & \\
First birth < 20 & 8.1 & 7.5 \\
Last birth > 40 & 7.4 & 5.2 \\
I-IIINM social class & 24.0 & 27.1 \\
IIIM-V social class & 24.3 & 27.1 \\
High education & 8.8 & 8.4 \\
Mean number of children & 3.8 & 2.4 \\
Presence of limiting & & \\
long-term illnesses & 22.1 & 20.2 \\
$N$ & 1820 & 80,434 \\
Women present in 2001 & & \\
Presence of limiting & & 38.3 \\
long-term illnesses & 44.6 & 19.0 \\
Poor self-rated health & 21.3 & 66,644 \\
$N$ & 1456 & \\
\hline
\end{tabular}

Note: Source: Office for National Statistics Longitudinal Study. 
Table 4

Effect of Having Multiple Birth on the Probability of Presence of Limiting Long-Term Illnesses in 1991 and 2001 and on the Probability of Poor Self-Rated Health in 2001 England and Wales

\begin{tabular}{|c|c|c|c|}
\hline \multirow[b]{2}{*}{ Year of birth } & \multicolumn{3}{|c|}{ Odds Ratios (95\% confidence interval) of having multiple births on: } \\
\hline & Long-term illnesses 1991 & Long-term illnesses 2001 & Poor self-rated health 2001 \\
\hline $1911-1920$ & $0.91(0.72-1.15)$ & $0.96(0.68-1.36)$ & $0.70(0.50-1.01)$ \\
\hline $1921-1930$ & $1.10(0.90-1.35)$ & $1.24^{*}(1.00-1.53)$ & $1.04(0.82-1.33)$ \\
\hline 1931-1940 & $0.93(0.72-1.19)$ & $1.25^{*}(1.02-1.53)$ & $1.12(0.87-1.44)$ \\
\hline 1941-1950 & $1.09(0.79-1.52)$ & $1.09(0.87-1.37)$ & $1.17(0.90-1.52)$ \\
\hline
\end{tabular}

Note: Controlling for marital status, social class, education, tenure, car access, age at first birth and intergenesic interval.

${ }^{*} p<.05$.

Source: Office for National Statistics Longitudinal Study.

Wales, which allowed control for covariates, suggested a small excess in mortality after age 45 among cohorts of mothers of twins born before 1920, as also shown in previous studies (Grundy \& Tomassini, 2005). When health was analyzed, again no higher risk of long-term illness for mothers of twins was found in 1991 and in 2001 only for women born between 1920 and 1940 .

It is possible that more recent generations of mothers of twins have benefited from better healthcare available in modern societies, so that the biological cost (in terms of health and mortality) of multiple births to mothers is not apparent anymore, while it may have been for past generations. Possibly, too, in the earlier cohorts, levels of nutrition were poorer and levels of physical strain higher, so that the additional maternal physical strain from bearing and rearing more than one child at once had an effect on health that has been buffered in more recent cohorts.

Apart from the inability to control for socioeconomic confounders in the Danish data, there are a number of other limitations of our data and analyses which need to be taken into account. We were able to observe the women in England and Wales only from 1971 onwards: older cohorts (e.g., those born between 1911 and 1920) include only survivors to that date and therefore it is not possible to observe potentially increased mortality in the years before 1971. The same problem exists for the Danish data, although linkage with the population register occurred slightly earlier in 1968. Moreover, our study focuses mainly on cohorts of women whose fertility careers predate the availability of fertility treatments. It is possible that health consequences are different for mothers of twins born as a result of interventions such as IVF. Further investigation is needed in the future to explore such associations. Finally, and importantly, the indicators of health used in this analysis may not capture psychological morbidity which other studies have suggested may be a consequence of having multiple births (Thorpe et al., 1991).

\section{Acknowledgments}

The work reported here was supported by the Economic and Social Research Council, UK, Grant
Reference Res-000-0394. We are grateful to the Office for National Statistics for access to data from the ONS Longitudinal Study; the project was approved by the Longitudinal Study Research Board. The authors alone are responsible for the interpretation of the data.

\section{$\overline{\text { References }}$}

Alonso, A. (2002). Long term health consequences of delayed childbirth: NHANES III. Women's Health Issues, 12, 37-45.

Basso, O., Christensen, K., \& Olsen, J. (2004). Fecundity of twinning. A study within the Danish National Birth Cohort. Human Reproduction, 19, 2222-2226.

Basso, O., Nøhr, E. A., Christensen, K., \& Olsen, J. (2004). Risk of twinning as a function of maternal height and body mass index. Journal of the American Medical Association, 291, 1564-1566.

Beral, V. (1985). Long term effects of childbearing on health. Journal of Epidemiology and Community Care, 39, 343-346.

Cooper, G., Baird, D., Weinberg, C., Ephross, S., \& Sandler, D. (2000). Age at menopause and childbearing patterns in relation to mortality. American Journal of Epidemiology, 151, 620-623.

Doblhammer, G. (2000). Reproductive history and mortality later in life: A comparative study of England and Wales and Austria. Population Studies, 54, 169-176.

Fellman, J., \& Eriksson, A. W. (2005). Variations in the maternal age effect on twinning rates: The Nordic experience. Twin Research and Human Genetics, 8, $515-523$.

Grundy, E., \& Tomassini, C. (2005). Fertility history and health in later life: A record linkage study in England and Wales. Social Science \& Medicine, 61, 217-228.

Hall, J. G., \& Lopez-Rangel, E. (1996). Twins and twinning. In D. L. Rimoin, J. M. Connor, \& R. E. Pyeritz (Eds.), Principles and practice of medical genetics (3rd ed., Vol. 1, pp. 395-404). New York: Churchill Livingstone. 
Hattersley, L., \& Creeser, R. (1995). Longitudinal study 1971-1991: History, organisation and quality of data. London: HMSO.

Herskind, A. M., Basso, O., Olsen, J., Skytthe, A., \& Christensen, K. (2005). Is natural twinning rate still declining? Epidemiology, 16, 591.

Kuh, D., \& Hardy, R. (2002). A life course approach to women's health. Oxford: Oxford Medical Publication.

Kvale, G., Heuch, I., \& Nilssen, S. (1994). Parity in relation to mortality and cancer incidence: A prospective study of Norwegian women. International Journal of Epidemiology, 23, 691-699.

Lambe, M., Wu, J., Rossing, M. A., \& Hsieh, C. C. (1999). Twinning and maternal risk of ovarian cancer. Lancet, 353, 1941.

Nasca, P. C., Weinstein, A., Baptiste, M., \& Mahoney, M. (1992). The relation between multiple births and maternal risk of breast cancer. American Journal of Epidemiology, 136, 1316-1320.

Neale, R. E., Darlington Murphy, M. F. G., Silcocks, P. B. S., Purdie, D. M., \& Talbäck, M. (2005). The effects of twins, parity and age at first birth on cancer risk in Swedish women. Twin Research and Human Genetics, $8,156-162$.

Neale, R. E., Purdie, D. M., Murphy, M. F. G., Mineau, G. P., Bishop, T., \& Whiteman, D. C. (2004). Twinning and the incidence of breast and gynaecological cancer (United States). Cancer Causes and Control, $15,829-835$.

Nygren, K. G., \& Nyboe Andersen, A. (2001). Assisted reproductive technology in Europe, 1997. Results generated from European registers by ESHRE, Human Reproduction, 16, 384-391.
Office for Population Censuses and Surveys (1987). Birth statistics 1837-1983, England and Wales, historical series, FM1, N.13. London: HMSO.

Olivennes, F. (2000). Double trouble: Yes a twin pregnancy is an adverse outcome. Human Reproduction, $15,1663-1665$.

Perls, T., Alpert, L., \& Fretts, R. (1997) Middle aged mothers live longer, Nature, 389, 133.

Riley, J. C. (2003). Did mothers begin with an advantage? A study of childbirth and maternal health in England and Wales, 1778-1929. Population Studies, 57, 5-20.

Sear, R, Shanley, D., McGregor, I., \& Mace, R. (2001). The fitness of twin mothers: Evidence from rural Gambia. Journal of Evolutionary Biology, 14, 433-443.

Skytthe, A., Kyvik, K., Holm, N. V., Vaupel, J. W., \& Christensen, K. (2002). The Danish twin registry: 127 cohorts of twins. Twin Research, 5, 352-357.

Snowdon, D. A., Kane, R. L., Beeson, W. L., Burke, G. L., Sprafka, J. M., Potter, J., Iso, H., Jacobs, D. R., Jr., \& Phillips, R. L. (1989). Is early natural menopause a biologic marker of health and aging? American Journal of Public Health, 79, 709-714.

Thorpe, K., Golding, J., MacGillivray, I., \& Greenwood, R. (1991). Comparison of prevalence of depression in mothers of twins and mothers of singletons. British Medical Journal, 302, 875-878.

Westergaard, T., Wohlfarhrt, J., Aaby, P., \& Melbye, M. (1997). Population based study of rates of multiple pregnancies in Denmark, 1980-94. British Medical Journal, 314, 775-779. 